\title{
Design and Evaluation of Zolpidem Tartrate Matrix Tablets for Extended Release Using Natural Gums and HPMC K100M
}

\author{
Siramsetti Dhanalakshmi, Srinivasa Rao Baratam* \\ St. Ann's College of Pharmacy, Andhra University, Cantonment, Vizianagaram 535003, Andhra Pradesh, India.
}

\begin{tabular}{l}
\hline ARTICLE INFO \\
\hline Article history: \\
Received on: 08/03/2018 \\
Accepted on: 23/05/2018 \\
Available online: $30 / 07 / 2018$
\end{tabular}

Key words:

Zolpidem tartrate, Natural

gums, HPMC K100M

matrix tablets and direct

compression.

\begin{abstract}
Zolpidem tartrate is a nonbenzodiazepine compound of sedative and hypnotic category used for the treatment of insomnia having a short half-life. Pre-compression parameters were evaluated. The tablets were evaluated for postcompression parameters such as thickness, hardness, average weight, friability and In vitro release studies. No interactions were observed between zolpidem tartrate and excipients from the Fourier transform infrared spectroscopy. The present research work was successful in improving the efficacy of zolpidem tartrate oral therapy as the drug release was extended for twelve hours thus reducing dosing frequency thereby improving patient compliance. The study also revealed the applicability of HPMC K100M, guar gum, and xanthum gum as rate-controlling polymers in matrix tablets. It may be concluded from the study that, formulation F7 (containing $10 \mathrm{mg}$ of xanthum gum) has shown zolpidem tartrate release over a period of $12 \mathrm{~h}$.
\end{abstract}

\section{INTRODUCTION}

Oral delivery of medication is most popular route because of the benefit of administration, patient compliance, and suppleness. Extended-release oral drug formulations are used since the Sixties to increase patient compliance (Pogula et al., 2010). Extended-release drug delivery system releases the drug over a longer period of time or the drug is penetrated or absorbed over an extended period of time (Pradhan et al., 2008). Extended releases adequate quantity of drug to induce the required blood concentration initially after the administration (loading dose, DL) for the required therapeutic response and thus, more quantity of drug is free at a controlled rate (maintenance dose, DM) to keep up the same blood levels for a few fascinating amount of time (Pogula et al., 2010). Zolpidem tartrate could be a nonbenzodiazepine analog of the imidazopyridine category. Zolpidem salt could be a gamma aminobutyric acid agonist utilized in the treatment of sleep disorder dose starting from 5 to

"Corresponding Author

Srinivasa Rao Baratam, M. Pharm., (Ph.D.), Asst. Professor, St. Ann's

College of Pharmacy, Andhra University Cantonment, Vizianagaram

535003, Andhra Pradesh, India.

E-mail:srinivas.baratam077@gmail.com
$12.5 \mathrm{mg}$. The half-life of the drug is regarding 1.9 to $3 \mathrm{~h}$, and oral bioavailability is $72 \pm 7 \%$ indicating its promising drive for the controlled-release formulation (Jayanthi et al., 2011). Zolpidem is used in decreasing the time to sleep, onset and increasing total sleep time; but, its effect on sleep maintenance has not been systematically explained (Scharf et al. 1994; Roth et al. 1995). The hypnotic effects of Zolpidem are reportable primarily within the 1 st three hours post-dose which might result in subtherapeutic effects on sleep maintenance within the later portion of the night for a few patients (Hardman et al., 2001). So, it is desired to maintain the plasma concentration of the drug for $12 \mathrm{~h}$. one of the foremost common approaches used for prolonging and dominant the fastness of drug release is to include a drug in a hydrocolloid matrix Hydroxypropyl methylcellulose (HPMC). Hence, within the work, an endeavor has been created to develop once-daily extended release matrix tablets of zolpidem victimization supposed colloidal matrix materials adore HPMC K100M and natural gums like guar and xanthum gum.

\section{MATERIALS AND METHODS}

\section{Materials}

Zolpidem tartrate was a gift sample from Aurobindo 
Pharma Ltd, Hyderabad, India. Hydroxypropyl methylcellulose (HPMC) K100M, Guar gum and Xanthum gum was obtained from Yarrow Chem. Products, Mumbai, India. Microcrystalline cellulose (MCC), magnesium stearate, and talc were purchased from Qualikems Fine Chemicals Pvt. Ltd, New Delhi. All other materials and chemicals used were of either pharmaceutical grade.

Table 1: Composition of Zolpidem tablets.

\begin{tabular}{|c|c|c|c|c|c|c|c|c|c|}
\hline \multirow{2}{*}{ Ingredients } & \multicolumn{9}{|c|}{ Formulation code } \\
\hline & F1 & F2 & F3 & F4 & F5 & F6 & F7 & F8 & F9 \\
\hline Zolpidem tartrate & 5 & 5 & 5 & 5 & 5 & 5 & 5 & 5 & 5 \\
\hline HPMC K100M & 10 & 20 & 30 & - & - & - & - & - & - \\
\hline Guar gum & - & - & - & 10 & 20 & 30 & - & - & - \\
\hline Xanthum gum & - & - & - & - & - & - & 10 & 20 & 30 \\
\hline $\mathrm{MCC}$ & 82 & 72 & 62 & 82 & 72 & 62 & 82 & 72 & 62 \\
\hline Magnesium stearate & 1 & 1 & 1 & 1 & 1 & 1 & 1 & 1 & 1 \\
\hline Talc & 2 & 2 & 2 & 2 & 2 & 2 & 2 & 2 & 2 \\
\hline Total weight of the tablet (mg) & 100 & 100 & 100 & 100 & 100 & 100 & 100 & 100 & 100 \\
\hline
\end{tabular}

\section{Methods}

A total of 9 formulations were prepared by direct compression technique in keeping with the formulas given Table 1. Sustained release matrix tablets of zolpidem tartrate were prepared by combining HPMC K100M, guar gum, and xanthum gum as matrix forming materials, whereas microcrystalline cellulose as a directly compressible dilutant, magnesium stearate as a lubricator and talc as an anti-adherent. All ingredients used were passed through 80 \# sieve, weighed and blended. The powders were prepared by direct compression technique and evaluated for its flow properties. The powdered mixture was compressed by using eight $\mathrm{mm}$ concave faced punches using in an eight-station compression machine (Shakti Pharmatech. Pvt. Ltd, Gujarat).

\section{Micromeritic evaluation}

The flow characteristics of powder (i.e., a mix of powders before compression) were assessed by measure the angle of repose by stationary funnel technique and Carr's compressibility index by normal standard tapping technique (Kirkwood et al., 2007; Chowdary et al., 2009). Hausner ratios were determined.

$$
\begin{aligned}
\text { Hausner ratio } & =\mathrm{Dt} / \mathrm{Db}, \\
\text { Compressibility Index }(\%) & =[(\mathrm{Dt}-\mathrm{Db}) \times 100] / \mathrm{Dt},
\end{aligned}
$$

where, Dt is the tapped density, Db is the bulk density.

\section{Drug content}

At random 5 tablets were chosen from completely different batches of formulations. The tablets were then pulverized, mixed by mortar. An accurately weighed amount of pulverized tablets was extracted with methanol and additional, the solution was diluted with Phosphate buffer $(\mathrm{pH} \mathrm{6.8).} \mathrm{The} \mathrm{solution} \mathrm{was}$ then filtered and created appropriate dilutions and absorbance was calculable at $237 \mathrm{~nm}$ (Chowdary et al., 2008). The results were shown in Table 4.

\section{Physical characterization}

The tablets were characterized for weight variation and thickness employing a screw-gauge micrometer, hardness employing a Pfizer hardness tester and friability employing a Roche friabilator equipment.

\section{In vitro release studies}

Procedure for in vitro dissolution

In vitro dissolution study of zolpidem tablets was performed by mistreatment USP equipment II (Lab India DS $8000)$. Paddle speed was maintained on 50 revolutions per minute at $37^{\circ} \mathrm{C} \pm 0.5^{\circ} \mathrm{C}$. The full amount of dissolution medium was $900 \mathrm{ml}$ maintained during the dissolution study Dissolution was conducted by the simulated gastric fluid as a medium for initial 2 hours and followed by phosphate buffer as a medium for the remaining hours. Samples were withdrawn at completely different preset time intervals and analyzed at $238 \mathrm{~nm}$ by UV Visible spectrophotometer. Quantity and proportion of drug dissolved were calculated (Mulagada et al., 2017).

\section{Fourier transformer infrared spectral analysis}

Compatibility studies of Zolpidem salt and therefore the excipients were administered by mistreatment Fourier Infrared spectroscopic analysis (FTIR). Fourier infrared spectra of the samples were obtained within the vary of 4000 to $450 \mathrm{~cm}^{-1}$ mistreatment an FTIR by KBr disc technique (Niazi, 2007).

\section{RESULTS AND DISCUSSIONS}

\section{Compatibility study}

Identification is carried out by FT-IR spectrum. FT-IR spectrum (shown in Table 2) of the pure drug was studied and characteristic absorption peaks obtained from $\mathrm{C}=\mathrm{C}$; $-\mathrm{CH} 3 ; \mathrm{C}=\mathrm{C}$; $=\mathrm{C}-\mathrm{H} ; \mathrm{C}=\mathrm{O} ; \mathrm{C}=\mathrm{N}$ etc. Groups were found to be confirmed the drug shown in Figure 1.

\section{Pre-compression parameters of zolpidem tartrate extended- release tablets}

Before preparation of matrix tablets of zolpidem tartrate, the powder mass is evaluated for flow properties. All the ready formulation showed well flow properties. The results obtained by 
evaluating the powder blends of drug and excipients were shown in Table 3. Bulk density and tapped density was found within the vary $0.50-0.56 \mathrm{~g} / \mathrm{ml}$ and zero. $62-0.69 \mathrm{~g} / \mathrm{ml}$ severally. The values of Carr's index and Hausner's quantitative relation was in between 1.16-1.25 and 0.11 to 0.25 indicating that each one batch of powder blends was having well squeezability. The values of the angle of repose $(\theta)$ were found in the range of 19.65-23.45 showing that the powder mix features a good flow.

\section{Post-compression parameters}

The results of the weight variation, hardness, thickness, friability and drug content were given in Table 4. The common weight of all the nine formulations was found to be $96.4 \mathrm{mg}$ to $102.56 \mathrm{mg}$. Altogether nine formulations, no tablets were outside the $\pm 10 \%$ of tablet weight in weight variation take a look at. The thickness varies between 2.41 to $2.72 \mathrm{~mm}$. Altogether formulations; tablet thickness of all formulations was among $\pm 5 \%$ of standard value. Friability values were below $\mathrm{I} \%$ in all cases.
The hardness of all the tablets was maintained at 5 to $6 \mathrm{~kg} / \mathrm{cm}^{2}$ for all the formulations. The assay was performed and drug content of all the tablets was found to be between ninety seven. 5\% and $100.38 \%$ of zolpidem tartrate. The drug content of the complete formulations was placed down within the range of $85-115 \%$.

Table 2: FT-IR interpretation of zolpidem tartrate and Optimized zolpidem tartrate tablets.

\begin{tabular}{|c|c|c|c|c|c|}
\hline \multirow{2}{*}{ S.No. } & \multirow{2}{*}{ Functional groups } & \multicolumn{2}{|c|}{$\begin{array}{c}\text { Characteristic peaks } \\
\text { (nm) }\end{array}$} & \multicolumn{2}{|c|}{$\begin{array}{c}\text { Observed peaks } \\
(\mathrm{nm})\end{array}$} \\
\hline & & Stretching & Bonding & Stretching & Bonding \\
\hline 1. & -CH3 & $3000-2840$ & $1340-1375$ & $2920-2868$ & 1334 \\
\hline 2. & $-\mathrm{C}=\mathrm{C}-$ & $2900-2950$ & $1400-1470$ & 2924 & 1456 \\
\hline 3. & $=\mathrm{C}-\mathrm{H}$ & $3050-3010$ & $900-690$ & 3053 & 895 \\
\hline 4. & $-\mathrm{C}=\mathrm{O}$ & $1680-1630$ & & 1635 & \\
\hline 5. & -O-H of Tartrate & $1400-1000$ & & 1396 & \\
\hline 6. & $=\mathrm{C}-\mathrm{N}$ & $1690-1640$ & & 1635 & \\
\hline
\end{tabular}

Table 3: Pre compression parameters of zolpidem tartrate extended-release tablets.

\begin{tabular}{|c|c|c|c|c|c|}
\hline Formulation Code & $\begin{array}{l}\text { Bulk Density } \\
(\mathrm{g} / \mathrm{ml})\end{array}$ & $\begin{array}{c}\text { Tapped Density } \\
(\mathrm{g} / \mathrm{ml})\end{array}$ & Carr's Index (\%) & Hausner Ratio & Angle of Repose ( $\theta)$ \\
\hline $\mathrm{F} 1$ & $0.55 \pm 0.011$ & $0.65 \pm 0.016$ & $1.25 \pm 0.024$ & $0.25 \pm 0.021$ & $23.45 \pm 0.14$ \\
\hline $\mathrm{F} 2$ & $0.54 \pm 0.02$ & $0.62 \pm 0.021$ & $1.19 \pm 0.036$ & $0.16 \pm 0.018$ & $19.65 \pm 0.21$ \\
\hline $\mathrm{F} 3$ & $0.56 \pm 0.014$ & $0.64 \pm 0.016$ & $1.23 \pm 0.045$ & $0.18 \pm 0.016$ & $22.35 \pm 0.24$ \\
\hline F4 & $0.54 \pm 0.024$ & $0.63 \pm 0.014$ & $1.12 \pm 0.042$ & $0.11 \pm 0.025$ & $20.69 \pm 0.18$ \\
\hline F5 & $0.50 \pm 0.021$ & $0.67 \pm 0.033$ & $1.24 \pm 0.036$ & $0.22 \pm 0.021$ & $20.82 \pm 0.32$ \\
\hline F6 & $0.53 \pm 0.012$ & $0.64 \pm 0.024$ & $1.23 \pm 0.036$ & $0.18 \pm 0.024$ & $20.72 \pm 0.23$ \\
\hline F7 & $0.51 \pm 0.032$ & $0.67 \pm 0.014$ & $1.24 \pm 0.044$ & $0.19 \pm 0.019$ & $20.89 \pm 0.17$ \\
\hline F8 & $0.52 \pm 0.021$ & $0.69 \pm 0.034$ & $1.30 \pm 0.051$ & $0.23 \pm 0.015$ & $20.78 \pm 0.33$ \\
\hline F9 & $0.56 \pm 0.041$ & $0.68 \pm 0.018$ & $1.21 \pm 0.029$ & $0.17 \pm 0.028$ & $22.6 \pm 0.21$ \\
\hline
\end{tabular}

$(\mathrm{n}=3$, mean \pm S.D $)$

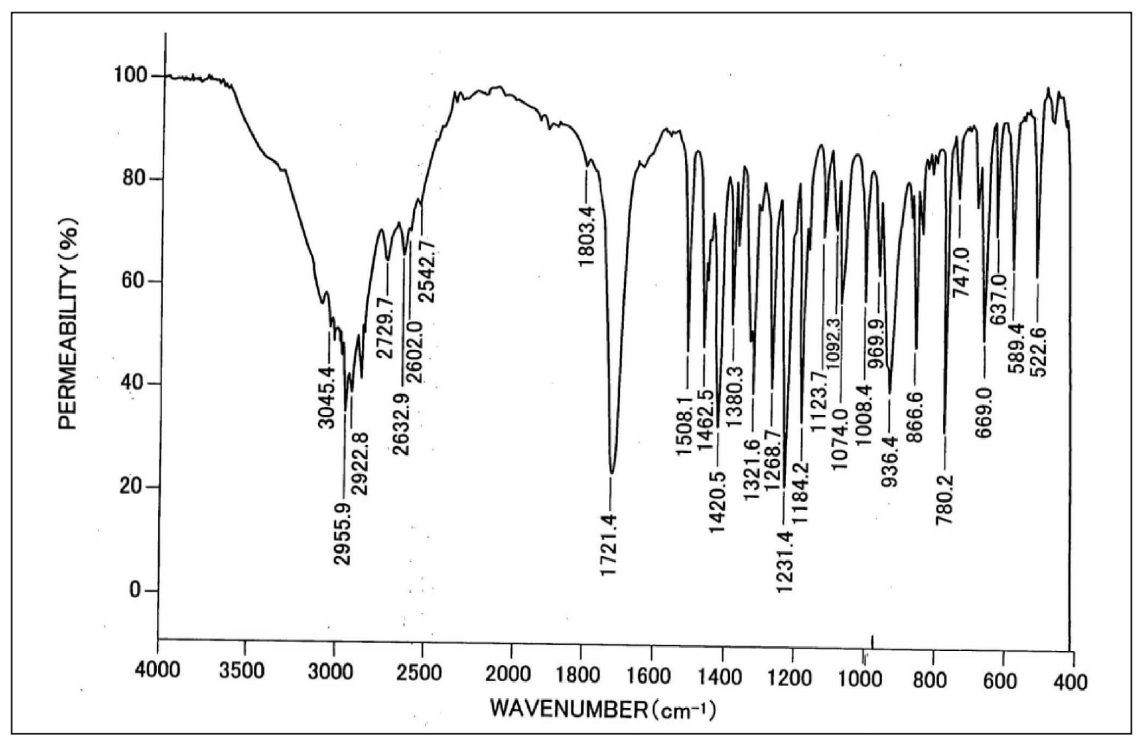

Fig. 1: FT-IR Curve of drug and polymer. 
Table 4: Post compression parameters of zolpidem tartrate extended release tablets.

\begin{tabular}{|c|c|c|c|c|c|}
\hline Formulation Code & Thickness (mm) & Average Weight (mg) & Friability (\%) & Hardness $\left(\mathrm{Kg} / \mathrm{cm}^{2}\right)$ & \% Drug Content \\
\hline $\mathrm{F} 1$ & $2.41 \pm 0.11$ & $99.6 \pm 0.54$ & $0.16 \pm 0.35$ & $5.4 \pm 0.43$ & $98.19 \pm 0.12$ \\
\hline $\mathrm{F} 2$ & $2.45 \pm 0.09$ & $98.75 \pm 0.45$ & $0.18 \pm 0.54$ & $5.5 \pm 0.64$ & $99.69 \pm 0.23$ \\
\hline F3 & $2.43 \pm 0.32$ & $101.67 \pm 0.23$ & $0.17 \pm 0.34$ & $5.3 \pm 0.43$ & $99.77 \pm 0.12$ \\
\hline $\mathrm{F} 4$ & $2.35 \pm 0.31$ & $96.40 \pm 0.64$ & $0.25 \pm 0.46$ & $5.6 \pm 0.45$ & $100.38 \pm 0.25$ \\
\hline F5 & $2.54 \pm 0.12$ & $102.56 \pm 0.34$ & $0.22 \pm 0.75$ & $5.3 \pm 0.34$ & $99.38 \pm 0.13$ \\
\hline F6 & $2.60 \pm 0.21$ & $99.67 \pm 0.54$ & $0.3 \pm 0.36$ & $6.0 \pm 0.65$ & $97.50 \pm 0.16$ \\
\hline F7 & $2.63 \pm 0.12$ & $97.40 \pm 0.35$ & $0.48 \pm 0.24$ & $5.6 \pm 0.23$ & $99.49 \pm 0.65$ \\
\hline F8 & $2.72 \pm 0.34$ & $100.89 \pm 0.43$ & $0.25 \pm 0.64$ & $5.5 \pm 0.21$ & $98.17 \pm 0.34$ \\
\hline F9 & $2.46 \pm 0.65$ & $101.7 \pm 0.53$ & $0.42 \pm 0.53$ & $5.0 \pm 0.12$ & $99.38 \pm 0.33$ \\
\hline
\end{tabular}

$(\mathrm{n}=3$, mean \pm S.D $)$.

Table 5: Dissolution profile of zolpidem tartrate ER tablets from F1 to F9.

\begin{tabular}{|c|c|c|c|c|c|c|c|c|c|}
\hline \multirow[t]{2}{*}{ Time (h) } & \multicolumn{9}{|c|}{ Formulation code } \\
\hline & F1 & F2 & F3 & F4 & F5 & F6 & F7 & F8 & F9 \\
\hline 0 & 0 & 0 & 0 & 0 & 0 & 0 & 0 & 0 & 0 \\
\hline 1 & $9.7 \pm 0.11$ & $10.5 \pm 0.53$ & $10.5 \pm 0.12$ & $18.5 \pm 0.11$ & $15.5 \pm 0.43$ & $10.2 \pm 0.22$ & $9.6 \pm 0.32$ & $21.2 \pm 0.23$ & $15.6 \pm 0.53$ \\
\hline 2 & $15.6 \pm 0.13$ & $15.8 \pm 0.34$ & $15.6 \pm 0.43$ & $24.6 \pm 0.45$ & $21.6 \pm 0.21$ & $18.6 \pm 0.65$ & $15.7 \pm 0.39$ & $35.4 \pm 0.65$ & $28.5 \pm 0.46$ \\
\hline 4 & $25.5 \pm 0.23$ & $26.9 \pm 0.24$ & $28.5 \pm 0.53$ & $35.6 \pm 0.23$ & $30.5 \pm 0.53$ & $26.12 \pm 0.23$ & $41.4 \pm 0.65$ & $46.7 \pm 0.12$ & $36.7 \pm 0.54$ \\
\hline 6 & $38.9 \pm 0.22$ & $49.8 \pm 0.64$ & $39.6 \pm 0.34$ & $41.7 \pm 0.54$ & $39.5 \pm 0.87$ & $38.7 \pm 0.12$ & $63.8 \pm 0.23$ & $58.9 \pm 0.55$ & $46.6 \pm 0.23$ \\
\hline 8 & $51.2 \pm 0.12$ & $70.2 \pm 0.45$ & $54.6 \pm 0.53$ & $60.7 \pm 0.21$ & $51.8 \pm 0.13$ & $50.7 \pm 0.54$ & $81.9 \pm 0.21$ & $67.9 \pm 0.49$ & $57.7 \pm 0.53$ \\
\hline 12 & $68.6 \pm 0.32$ & $85.4 \pm 0.63$ & $68.9 \pm 0.23$ & $78.9 \pm 0.74$ & $70.9 \pm 0.43$ & $64.4 \pm 0.23$ & $96.4 \pm 0.45$ & $81.5 \pm 0.53$ & $71.8 \pm 0.23$ \\
\hline
\end{tabular}

$(\mathrm{n}=3$, mean \pm S.D $)$.

\section{In vitro dissolution}

In vitro dissolution studies performed for extended-release tablets of zolpidem tartrate mixture of solvent $0.01 \mathrm{~N} \mathrm{HCI}$ for initial 2 hours and followed by phosphate buffer victimization USP dissolution equipment II. Percentage drug release profiles were shown in Table 5. Drug release varies because of completely different concentrations of releasing polymer/gum in the formulations. In Figure 2, it absolutely was determined that with a rise in polymer/gum concentration, there was a decrease in the release. First order release profiles were shown in Figure 3. Formulations F1, F2, and F3 prepared by using HPMC $\mathrm{K} 100 \mathrm{M}$ show $68.6 \%, 85.4 \%$, and $68.9 \%$ of the drug at the end of twelve hours. Formulations F4, F5, and F6 ready by using guar gum shows $78.9 \%, 70.9 \%$, and $64.4 \%$ of the drug at the end of twelve hours. Formulations F7, F8, and F9 prepared by using xanthum gum show $96.4 \%, 81.5 \%$, and $71.8 \%$ of the drug at the end of twelve hours. Formulation F7 was thought-about as optimized formulation releases $96.4 \%$ of the drug at the end of twelve hours. The dissolution rate was found to extend linearly with increasing concentration of polymer/ gum. Formulation F7 containing xanthum gum of ten mg as a release rate retardant was taken as optimized formulation.

Zero-order rate equation describes release rate is freelance of the concentration of dissolved materials (Mulagada et al., 2017). The first-order equation describes the discharge from systems wherever the dissolution rate depends on the concentration of the dissolving species (Shanyang, 1988; Ranga et al., 1988). The Korsmeyer Peppas equation is employed to investigate the discharge of a pattern of the drug in indefinite quantity forms.
The Higuchi root equation describes the discharge from systems wherever the solid drug is distributed in associate in the insoluble matrix, and also the rate of drug release is said to the speed of drug diffusion (Higuchi et al., 1963).

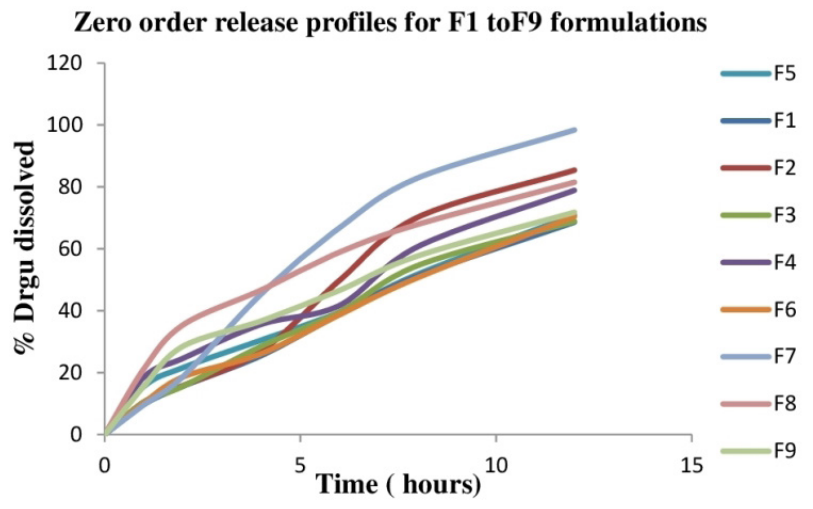

Fig. 2: In vitro analysis for all formulations.

Release information was fitted to varied mathematical models to evaluate the dynamics and mechanisms of the drug release were shown in Table 6 . The $\left(\mathrm{R}^{2}\right)$ values for optimized formulation F7 obtained from zero order kinetics was found to be 0.989 and is more than first-order kinetics 0.974 , indicates zero order release. The $\left(\mathrm{R}^{2}\right)$ values for optimized formulation $\mathrm{F} 7$ from Higuchi, Peppas was found to be 0.969 and 0.993, it absolutely was evident that the drug was released by non-fickian diffusion 
mechanism followed by erosion. Higuchi and Peppas plots for all formulations were shown in Figures 4 and 5. The slope (n) 0.901, indicating that non-fickian diffusion (anomalous) Super case -II was the drug release mechanism from the optimized formulation. Hence, non fickian diffusion, as well as erosion, may well be the mechanism of drug release from optimized sustained release matrix tablets prepared by xanthum gum (Priyanka et al., 2016; Koesmeyer et al., 1983).

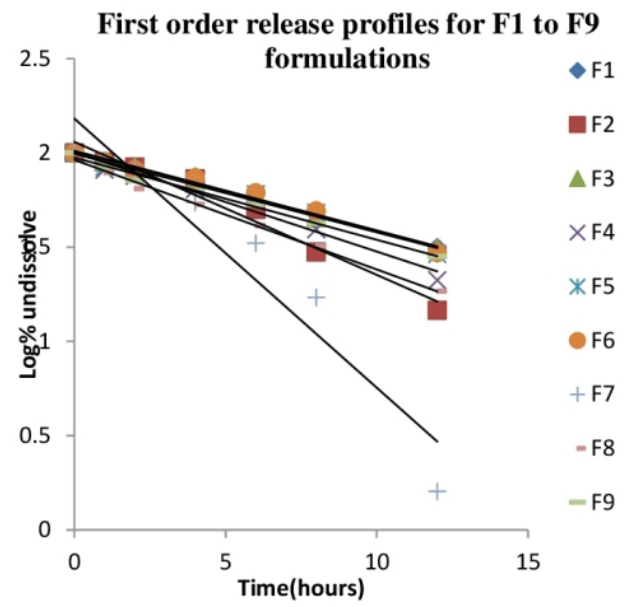

Fig. 3: First order release analysis for all formulations.

Table 6: Kinetics of drug release from zolpidem tartrate ER tablets F1 to F9.

\begin{tabular}{cccccc}
\hline Formulation code & Zero Order & First order & Higuchi & \multicolumn{2}{c}{ Peppas } \\
\hline & $\left(\mathbf{R}^{2}\right)$ & $\left.\mathbf{( R}^{2}\right)$ & $\left.\mathbf{( R}^{2}\right)$ & $\left.\mathbf{( R}^{2}\right)$ & $\mathbf{n}$ \\
\hline F1 & 0.995 & 0.994 & 0.971 & 0.997 & 0.801 \\
F2 & 0.987 & 0.982 & 0.955 & 0.987 & 0.899 \\
F3 & 0.992 & 0.980 & 0.975 & 0.996 & 0.788 \\
F4 & 0.983 & 0.979 & 0.980 & 0.984 & 0.579 \\
F5 & 0.988 & 0.971 & 0.983 & 0.991 & 0.603 \\
F6 & 0.995 & 0.982 & 0.973 & 0.995 & 0.760 \\
F7 & 0.989 & 0.974 & 0.969 & 0.993 & 0.897 \\
F8 & 0.996 & 0.950 & 0.991 & 0.995 & 0.52 \\
F9 & 0.995 & 0.967 & 0.995 & 0.992 & 0.588 \\
\hline
\end{tabular}

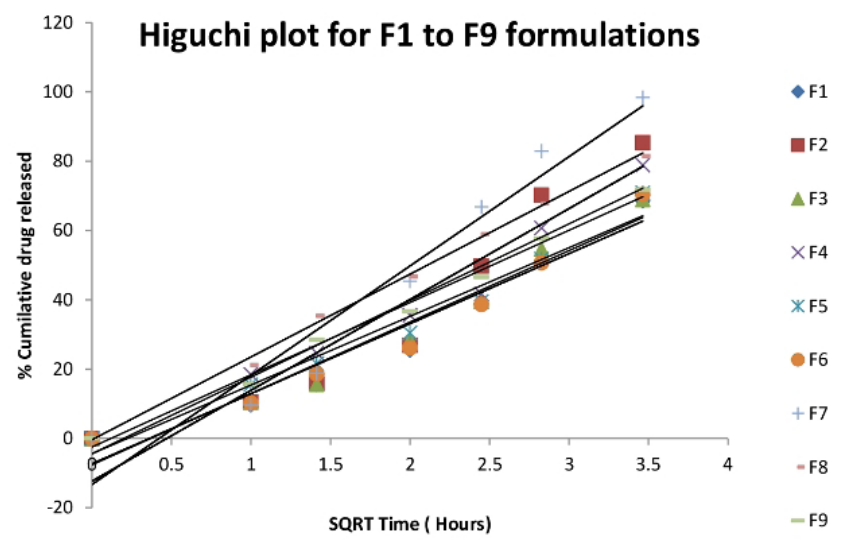

Fig. 4: Higuchi model of drug release from various formulations.

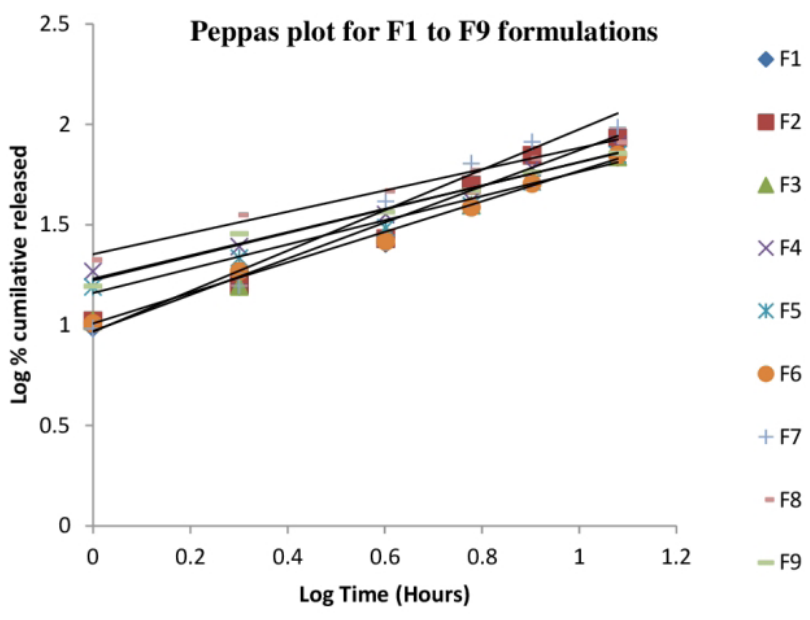

Fig. 5: Korsmeyer peppas model of drug release from various formulations.

\section{CONCLUSION}

The present research work was successful in improving the efficacy of zolpidem tartrate oral therapy as the drug release was extended for twelve hours thus reducing dosing frequency thereby improving patient compliance. The study also revealed the applicability of HPMC K100M, guar gum, and xanthum gum as rate-controlling polymers in matrix tablets. It may be concluded from the study that, formulation F7 (containing $10 \mathrm{mg}$ of xanthum gum) has shown zolpidem tartrate release over a period of $12 \mathrm{~h}$.

\section{CONFLICT OF INTERESTS}

There is no conflict of interest.

\section{FINANCIAL SUPPORT AND SPONSORSHIP} Nil.

\section{REFERENCES}

Chowdary KPR, Tripura Sundari P, Surya Prakasa Rao K. Formulation and Evaluation of Piroxicam and Celecoxib Tablets employing Prosolve by Direct Compression Method. International Journal of Chemical Sciences, 2008; 6:1270-75.

Chowdary KPR, Tripura Sundari P, Surya Prakasarao K. Formulation and evaluation of piroxicam and aceclofenac tablets employing Prosolve by direct compression method. Asian Journal of Chemistry, 2009; 21:5847-50.

Chowdary KPR, Rao KSP. Formulation Development of Pioglitazone Tablets Employing $\beta$ Cyclodextrin-Poloxamer 407-PVP K30: A Factorial Study. Scholars Research Library, 2011; 3(6):24-30.

Higuchi T. Mechanism of sustained-action medication: Theoretical analysis of the rate of release of solid drugs dispersed in solid matrices, J Pharm Sci, 1963; 52:1145-49.4

Koesmeyer RW, Gurny R, Doelker E, Buri P, Peppas NA. Mechanism of solute release from porous hydrophilic polymers. Int $J$ Pharm, 1983; 15:25-35.

Hardman JG, Limbrid LE, Goodman A, Molinoff PB, Ruddon RW. 2001. The Pharmacological Basis of Therapeutics. New York, USA: Macgraw-Hill.

Higuchi T. Mechanism of sustained-action medication: Theoretical analysis of the rate of release of solid drugs dispersed in solid matrices, J Pharm Sci, 1963; 52:1145-49.

Jayanthi B, Manna PK, Madhusudhan S, Mohanta GP, Manavalan R. Per oral extended release products -An overview. Journal of 
Applied Pharmaceutical Science, 2011; 01:50-55.

Kirkwood C, Neill J, Breden E. Zolpidem modified release in insomnia. Neuropsychiatric Disease and Treatment, 2007; 3:521-26.

Koesmeyer RW, Gurny R, Doelker E, Buri P, Peppas NA. Mechanism of solute release from porous hydrophilic polymers. Int $\mathrm{J}$ Pharm, 1983; 15:25-35.

Manish R Bhise. Development and evaluation of film coated extended release zolpidem tartrate tablet by direct compression technology. Asian J Pharm Clin Res, 2012; 5:82-85.

Mulagada S, Baratam SR. Design and Evaluation of Ondansetron Fast Disintegrating Tablets Using Natural Polymers and Modified Starches as Super Disintegrants for the Enhancement of Dissolution. J Young Pharm, 2017; 9:446-50.

Niazi SK. 2007. Handbook of Preformulation. New York, USA: Informa Healthcare.

Pogula M, Nazeer S. Extended release formulation. Int J Pharm Tech, 2010; 2:625-84.

Pradhan R, Budhathoki U, Thapa P. Formulation of once a day controlled release tablet indomethacin based on HPMC mannitol. Eng Tech, 2008; 1:55-67.

Priyanka K, Surya Prakasarao K, Kalyan Chakravarthy J. Formulation and optimization of controlled release paroxetine hydrochloride tablets using response surface methodology. Journal of Global Trends in Pharmaceutical Sciences, 2016; 7(4):3520-34.

Ranga KV, Padmalatha DK, Buri P. Cellulose matrices for zero order release of soluble drugs. Drug Dev Ind Pharm, 1988; 14:2299-2320.

Roth T, Roehrs T, Vogel G. Zolpidem in the treatment of transient insomnia: A double-blind, randomized comparison with placebo. Sleep, 1995; 18:246-51.

Shanyang L. Effect of excipients on tablet properties and dissolution behavior of theophylline tableted microcapsules under different compression forces. J Pharm Sci, 1988; 77:229-32.

Scharf MB, Roth T, Vogel GW, et al. A multicenter, placebocontrolled study evaluating zolpidem in the treatment of chronic insomnia. J Clin Psychiatry, 1994; 55:192-9.

\section{How to cite this article:}

Dhanalakshmi S, Baratam SR. Design and Evaluation of Zolpidem Tartrate Matrix Tablets for Extended Release Using Natural Gums and HPMC K100M. J App Pharm Sci, 2018; 8(07): 072-077. 